\title{
Do responses to exercise training in cystic fibrosis depend on initial fitness level?
}

\author{
W. Gruber*, D.M. Orenstein ${ }^{\#}$ and K.M. Braumann*
}

\begin{abstract}
The aim of our study was to evaluate the responses to an exercise programme with respect to initial fitness in subjects with cystic fibrosis (CF).
\end{abstract}

72 subjects (42 female) aged 10-43 yrs (forced expiratory volume in $1 \mathrm{~s}$ of $62.0 \pm 26.7 \%$ predicted) were included. Participants were divided into three groups based on peak oxygen uptake expressed as $\%$ predicted. Subjects participated in a multifaceted rehabilitation programme, including five-times-a-week exercise training, for 6 weeks. Exercise and ventilatory capacity were determined by a maximal incremental cycling test. Oxygen uptake, workload and peak cardiac frequency at peak and submaximal workload were used as parameters for exercise capacity and responsiveness to training.

Lung function values were significantly different between groups $(p<0.05)$, and increased after training $(p<0.05)$ only in groups with a lower initial fitness level. Responsiveness to training showed differences between groups $(p<0.05)$ at peak and ventilatory anaerobic threshold (VAT; $\mathbf{p}<\mathbf{0 . 0 5}$ ), with higher improvements in subjects with lower initial fitness level.

The improvements in exercise parameters in CF at peak and VAT depended on the fitness level at baseline, independent of lung function. These improvements seen after training were comparable with those seen in healthy subjects, suggesting that responsiveness to exercise is similar in CF and in healthy untrained persons.

KEYWORDS: Cystic fibrosis, exercise capacity, exercise programme, fitness level, responsiveness, trainability

xercise or regular physical activities have a number of potential beneficial effects in cystic fibrosis (CF), including improved aerobic capacity, flexibility, coordination, muscular strength, lung function and quality of life [1-4]. Despite our knowledge about the beneficial effects of exercise training and the factors leading to exercise intolerance in $\mathrm{CF}$, there have been few studies on the effects of exercise training on exercise capacity with respect to subjects' baseline fitness level.

In healthy populations, the initial level of fitness seems to determine the physiological training response. Healthy people with lower peak oxygen uptake $\left(V^{\prime} \mathrm{O}_{2}\right.$,peak) can improve more than those who have already trained or are physically active [5]. In subjects with $\mathrm{CF}$, a positive relationship between physical activity and $V^{\prime} \mathrm{O}_{2}$,peak has been found [6, 7]. However, little information is available concerning the benefits of an exercise programme in relation to disease severity or fitness levels in CF. CERNY et al. [8] found a similar improvement in exercise capacity in subjects with moderate and severe pulmonary disease after an in-patient hospitalisation, but a greater improvement in lung function in the severely affected subjects.

We recently showed a positive relationship between initial fitness level and improvement in maximal exercise capacity in CF [9]. These studies suggest that responsiveness to exercise training in people with CF depends on initial fitness level and lung function, with greater benefits in those people with lower fitness level and lung function. However, it is still unclear whether similar responses to exercise training occur at submaximal workloads. Thus, the objective of the present study was to examine physiological training responses in $\mathrm{CF}$ at maximum and submaximal workloads in relation to pre-training fitness level.

\section{MATERIALS AND METHODS}

\section{Subjects}

72 participants (42 female) with CF aged 10-43 yrs were included (table 1). The data were assessed during a 6-week in-patient rehabilitation course in a specialised CF institution (Fachklinik Satteldüne, Nebel Amrum, Germany). Participants were in a stable condition, and home medication (inhaled or oral antibiotics, bronchodilators, pancreatic
AFFILIATIONS

*Institute for Sports and Exercise Medicine, University of Hamburg, Hamburg, Germany.

${ }^{\#}$ School of Medicine, University of Pittsburgh, Pittsburgh, PA, USA

CORRESPONDENCE

W. Gruber

Institute for Sports and Exercise Medicine

University of Hamburg

Mollerstr. 2

20148 Hamburg

Germany

E-mail: gruber-wolfgang@

t-online.de

Received:

Dec 142010

Accepted after revision:

May 042011

First published online:

May 262011 


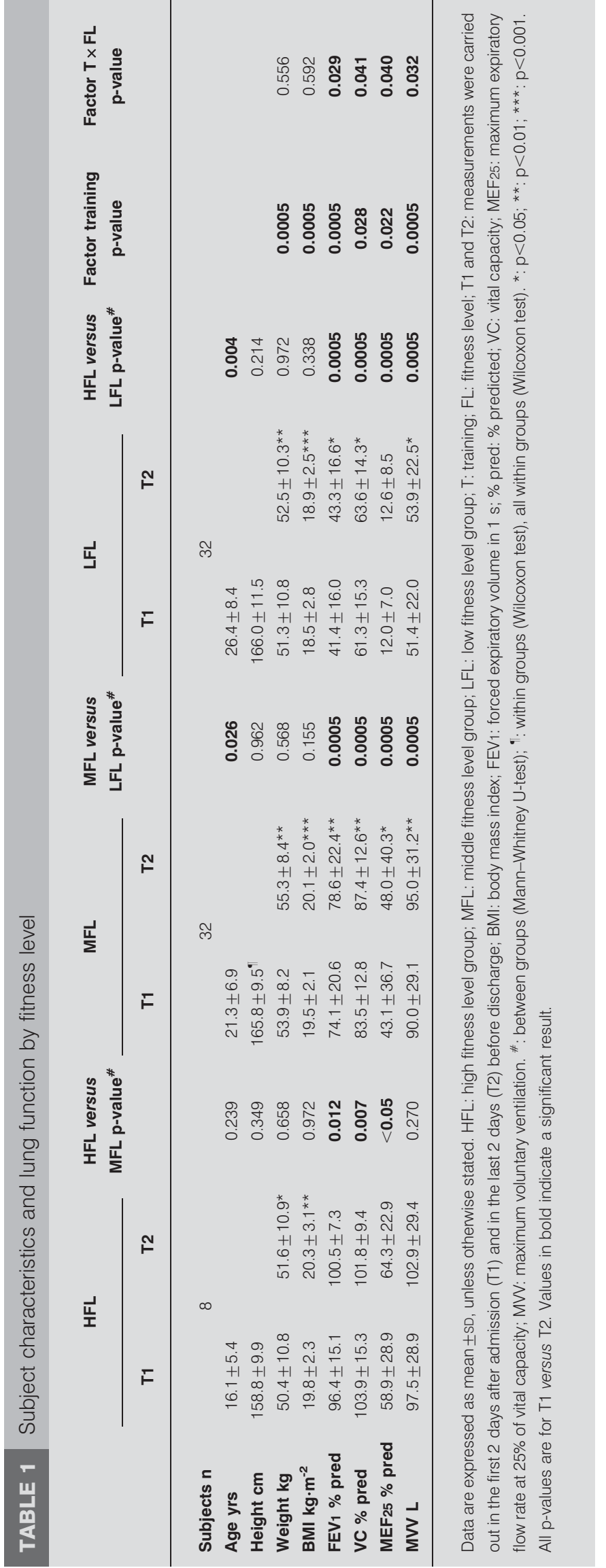

enzyme supplements and vitamins) was continued unchanged throughout the rehabilitation.

Individuals were included if: 1 ) age was $\geqslant 10 \mathrm{yrs}$; 2) height was $\geqslant 120 \mathrm{~cm} ; 3$ ) their overall health was stable throughout the study period; and 4) they had no acute exacerbation in the 4 weeks prior to the in-patient programme. Exclusion criteria were as follows: 1) untreated CF-related diabetes; 2) heart problems; 3) 24-h oxygen requirement; 4) intravenous antibiotic therapy in the 4 weeks prior to the programme; or if 5) their ventilatory anaerobic threshold (VAT) could not be identified. Subjects were divided into three groups based on their initial fitness level. For allocation, the same reference equation was used as in the study of NixON et al. [10, 11]. The "high fitness level group" (HFL) consisted of those subjects with a $V^{\prime} \mathrm{O}_{2}$,peak of $\geqslant 82 \%$ predicted, the "middle fitness level group" (MFL) was those with initial $V^{\prime} \mathrm{O}_{2}$,peak $59-81 \%$ pred, and the "low fitness level group" (LFL) was those participants with a $V^{\prime} \mathrm{O}_{2}$,peak $\leqslant 58 \%$ pred [10].

The study was approved by the Ethics Committee of the Medical Chamber of Schleswig-Holstein, Germany, and written informed consent was obtained for each subject, either from the subject themselves or from the subject's parents or guardians, prior to the rehabilitation course.

\section{Study design and methods}

All measurements were carried out in the first 2 days after admission (T1) and in the last 2 days before discharge (T2). Measurements of lung function were performed according to the guidelines of the European Respiratory Society [12]. Forced expiratory volume in $1 \mathrm{~s}$ (FEV1), vital capacity (VC) and maximum expiratory flow rate at $25 \%$ of vital capacity (MEF25) were measured by spirometry (MasterScreen; Jaeger, Würzburg, Germany) and values were expressed as mean \% predicted of the normal values [12]. Maximal voluntary ventilation (MVV) was calculated as FEV1 [1] × 35 [13].

All subjects completed an incremental cycling test (cardiopulmonary exercise test; CPET) (Examiner, Lode, Groningen, the Netherlands) to determine cardiopulmonary parameters at peak and submaximal exercise capacity. After a 3-min rest period and after $3 \mathrm{~min}$ of unloaded cycling, work rate was increased every minute by 10-20 W (the Godfrey protocol), depending on the patient's height and physical fitness [14]. Participants were encouraged to make a maximal effort, and the test was continued until the subject could no longer maintain a pedalling cadence of $60 \mathrm{rpm}$.

The following measurements were made breath by breath (MasterScreen CPX; Viasys Healthcare, Hoechberg, Germany): oxygen uptake $\left(V^{\prime} \mathrm{O}_{2}\right.$ in $\mathrm{mL} \cdot \mathrm{min}^{-1}$ and $\left.\mathrm{mL} \cdot \mathrm{kg}^{-1} \cdot \mathrm{min}^{-1}\right)$, minute ventilation $\left(V^{\prime} \mathrm{E}\right.$ in $\left.\mathrm{L}\right)$, respiratory rate $(f \mathrm{R}$ in $\mathrm{min})$, tidal volume $(V \mathrm{~T}$ in $\mathrm{mL}$ ), respiratory exchange ratio (RER equal to carbon dioxide production $\left./ V^{\prime} \mathrm{O}_{2}\right), \mathrm{O}_{2}$ pulse (in $\mathrm{mL}$ ), and ventilatory equivalent for oxygen $\left(V^{\prime} \mathrm{E} / V^{\prime} \mathrm{O}_{2}\right)$. Breathing reserve $\left(V^{\prime} \mathrm{E} / \mathrm{MVV}\right.$ in \%) at maximal and submaximal workloads was calculated. Cardiac frequency $(f C)$ was measured continuously on a 12-lead ECG. Workload ( $W$ in $W$ and $W \cdot \mathrm{kg}^{-1}$ ) was determined as the highest work level reached at peak or VAT. The peak exercise variables were specified as the highest value in the last $30 \mathrm{~s}$ before stopping the test. Before each exercise test the metabolic 
cart was calibrated with gases of known concentration $\left(\mathrm{O}_{2}\right.$, $21.0 \% ; \mathrm{CO}_{2}, 5.0 \% ; \mathrm{N}_{2}, 74 \%$ ).

A test was accepted as near maximal or truly maximal if any of the following objective criteria were met: 1) $f c \geqslant 90 \%$ of agepredicted maximum; 2) RER at test termination $\geqslant 1.05$; and 3) peak $V^{\prime} E$ at test termination $\geqslant 65 \%$ of $\operatorname{MVV}[13,15]$.

To determine outcome variables at the VAT, the excess carbon dioxide method and the modified V-slope method were used [16, 17]. Two experienced persons independently determined the VAT using these methods and results were compared with the data identified using computer algorithm methods.

\section{Exercise training programme}

Participants exercised five times weekly for 6 weeks under the supervision of a specialised sport-therapist. Each training session lasted $45 \mathrm{~min}$ and consisted of different sport activities depending on age and fitness level (jogging, walking/Nordic walking, ball and running games, stretching, balance training, resistance training and swimming). Training intensity during jogging/ walking sessions was between $80-90 \%$ of the VAT and was monitored with a portable $f C$ monitor (Polar Electro, Kempele, Finland).

The exercise programme was part of an intensive treatment regimen. All subjects received daily chest physiotherapy for 30-60 min once to twice a day, and a high-energy diet with nutritional supplements according to disease severity and nutritional status.

\section{Statistical analysis}

Data are presented as mean \pm SD. The data were evaluated with repeated-measures analyses of variance (MANOVA) with fitness level as the between-group factor and training as the within-group factor. If a significant result was noticed for the between-group factor, a Scheffé post hoc test was used to compare groups. In case of significance for the factor "training", a Wilcoxon's signed rank test was applied for within-group comparison. The strength of the correlations between initial $V^{\prime} \mathrm{O}_{2}$,peak (in $\mathrm{mL} \cdot \mathrm{kg}^{-1} \cdot \mathrm{min}^{-1}$ ) and change in oxygen uptake $\left(\Delta V^{\prime} \mathrm{O}_{2}\right.$; in $\left.\mathrm{mL} \cdot \mathrm{kg}^{-1} \cdot \mathrm{min}^{-1}\right), V^{\prime} \mathrm{O}_{2}$ at VAT and $V^{\prime} \mathrm{O}_{2}$,peak (in $\mathrm{mL} \cdot \mathrm{kg}^{-1} \cdot \mathrm{min}^{-1}$ ), and between FEV1 and $\Delta V^{\prime} \mathrm{O}_{2}$ (in $\mathrm{mL} \cdot \mathrm{kg}^{-1} \cdot \mathrm{min}^{-1}$ ) were calculated using Pearson's correlation coefficient. All statistical analyses were computed with SPSS version 15.0 (SPSS Inc., Chicago, IL, USA). A p-value of $<0.05$ was considered statistically significant.

\section{RESULTS}

Characteristics of the participants are shown in table 1 . Subjects of MFL and LFL were older than those of HFL $(p<0.05$; table 1$)$. No significant differences between the groups were found for height and weight at T1 and at T2 $(\mathrm{p}>0.05)$. All groups gained weight and body mass index during the programme $(p<0.001)$ and showed similar improvements (training $(\mathrm{T}) \times$ fitness level $(\mathrm{FL}) ; \mathrm{p}>0.05$ ). At $\mathrm{T} 1$ and $\mathrm{T} 2$ the lung function values differed between groups $(\mathrm{p}<0.05)$. FEV1, VC, MEF25 and MVV were higher in the HFL $(\mathrm{p}<0.05)$ group compared with the MFL and LFL groups. MFL showed better values in all lung function parameters compared with the LFL group $(p<0.05)$. At the end of the inpatient course a significant interaction, $\mathrm{T} \times \mathrm{FL}$, was found $(p<0.05$; table 1). Improvements in the MFL and LFL groups were higher than in HFL. Lung function values in the HFL group did not change significantly $(\mathrm{p}>0.05)$. An improvement in MEF25 was seen only in the MFL group $(p<0.05)$. The baseline and post-training values for fitness measures are shown in tables 2 and 3. Fitness at peak and VAT differed between groups $(\mathrm{p}<0.05$; tables 2 and 3$)$. With the exception of peak $f C$, all peak fitness values in HFL and MFL groups were significantly higher compared with the LFL group $(\mathrm{p}<0.05)$. Fitness values in the HFL group were nonsignificantly better than those of the MFL group $(\mathrm{p}>0.05)$. The respiratory measurements at peak included significantly lower $V^{\prime} \mathrm{E}$ and $V \mathrm{~T}$ in LFL compared with MFL and HFL $(\mathrm{p}<0.05)$. No differences were found between the HFL and MFL groups. Younger subjects in the HFL group showed the highest values for $f \mathrm{R}$, whereas the values of the MFL and LFL groups were nearly identical. $V^{\prime} \mathrm{E} / \mathrm{MVV}$ increased with reduction in physical fitness, and values in the MFL and LFL groups especially were higher than those of healthy people at maximum exercise. RER and $V^{\prime} \mathrm{E} / V^{\prime} \mathrm{O}_{2}$ were similar between groups.

As in peak exercise capacity, the HFL group showed better fitness values than MFL and LFL at VAT. There was no significant difference between the HFL and MFL groups except for in WVAT $\left(\mathrm{W} \cdot \mathrm{kg}^{-1} ; \mathrm{p}<0.05\right)$, whereas the LFL group had the lowest fitness values compared with the HFL and MFL groups $(\mathrm{p}<0.05)$. The respiratory parameters at VAT were similar between groups $(\mathrm{p}>0.05)$. $V^{\prime} \mathrm{E} / \mathrm{MVV}$ increased with decreased fitness level and differed significantly between groups $(p<0.05)$, and it increased significantly from pre- to post-training in MFL and LFL.

In all groups, with exception of peak $f C$ and at the VAT, the fitness level values improved from baseline by 6 weeks. However, there was a significant $\mathrm{T} \times \mathrm{FL}$ interaction, reflecting different changes between the groups ( $p<0.05$; tables 2 and 3 ). Fitness variables at peak and VAT improved significantly in the MFL and LFL groups $(p<0.05)$, but only minor changes were seen in the HFL group $(p>0.05)$ after training.

There were only small nonsignificant improvements in respiratory parameters and a positive time-effect was observed only for $V^{\prime} \mathrm{E} / \mathrm{MVV}$ at VAT $(\mathrm{p}<0.05)$. The Wilcoxon's signed rank test revealed a significant result only in the LFL group $(\mathrm{p}<$ 0.05). Using Spearman's correlations, a positive relationship was found $(\mathrm{r}=0.432, \mathrm{p}<0.05$; fig. 1$)$ between initial $V_{\mathrm{O}_{2}}$, peak $\left(\mathrm{mL} \cdot \mathrm{kg}^{-1} \cdot \mathrm{min}^{-1}\right)$ and $\Delta V^{\prime} \mathrm{O}_{2}\left(\mathrm{~mL} \cdot \mathrm{kg}^{-1} \cdot \mathrm{min}^{-1}\right)$. No significant correlation emerged between FEV1 (\% pred) and $\Delta V^{\prime} \mathrm{O}_{2}$ $\left(\mathrm{mL} \cdot \mathrm{kg}^{-1} \cdot \mathrm{min}^{-1} ; \mathrm{r}=0.202, \mathrm{p}=0.79\right.$; fig. 2$)$. FEV1 (\% pred) was found to correlate positively with $V^{\prime} \mathrm{O}_{2}$,peak $\left(\mathrm{mL} \cdot \mathrm{min}^{-1} ; \mathrm{r}=0.6\right.$, $\mathrm{p}<0.05$; fig. 3).

\section{DISCUSSION}

To date, little information has been available concerning the influence of disease severity on the benefits of an exercise programme in CF. CERNY et al. [8] showed a significant improvement in lung function in severely affected subjects with $\mathrm{CF}$ after a 2-week exercise programme during hospitalisation for treatment of CF pulmonary exacerbations, during which time they also received i.v. antibiotics and intensive airway clearance. The authors found a significant improvement in peak work capacity in subjects with moderate-to-severe pulmonary function 

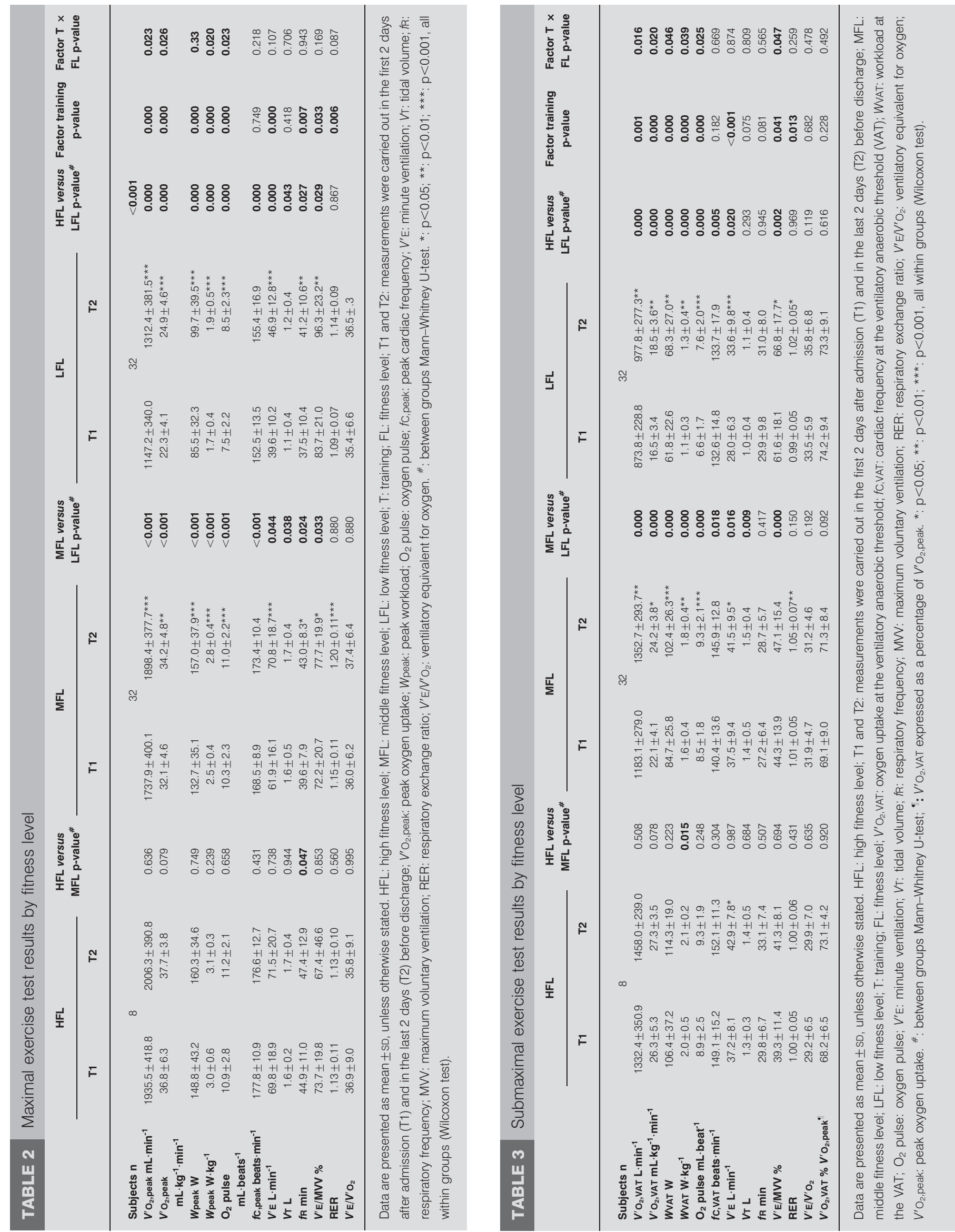


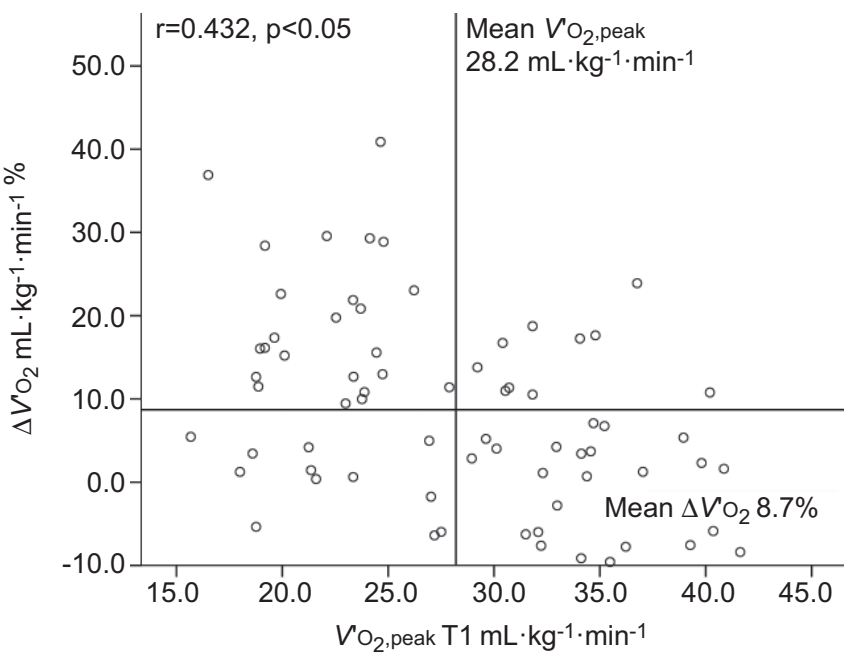

FIGURE 1. Relationship between peak oxygen uptake $\left(V^{\prime} \mathrm{O}_{2}\right.$,peak $)$ at baseline (T1) and change in oxygen uptake $\left(\Delta V^{\prime} \mathrm{O}_{2}\right)$.

abnormality and those with severe abnormalities, but the improvements were equivalent between groups. In their study, CERNY et al. [8] allocated the participants into groups based on a pulmonary lung function score including several lung function parameters, and not on initial fitness. We recently reported greater improvement of $V^{\prime} \mathrm{O}_{2}$,peak in those subjects with CF who had a lower fitness level and lower lung function [9]. Participants in that study [9] performed the same type of training during an in-patient rehabilitation course, but in contrast to the present study, we neither reported on changes of pulmonary parameters during exercise nor examined the effects on cardiopulmonary parameters at submaximal workloads. The results of the present study are an extension of the recently published study [9].

The results of this 6-week exercise training study demonstrated a beneficial effect on peak and submaximal exercise capacity, lung function and, to a smaller degree, on ventilatory parameters in $\mathrm{CF}$, with a wide range of fitness levels and lung function impairment. The improvement in exercise tolerance is

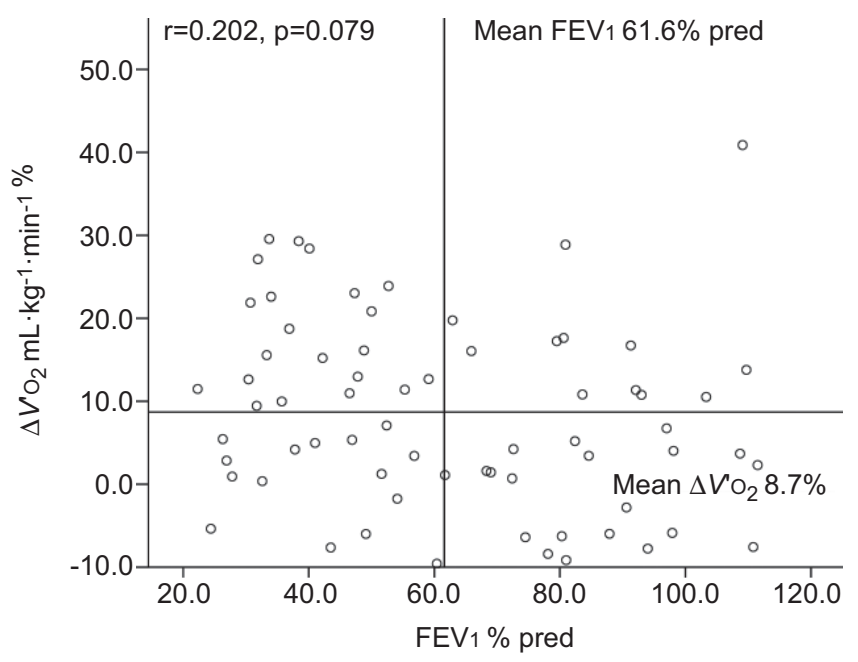

FIGURE 2. Relationship between change in oxygen uptake $\left(\Delta V^{\prime} \mathrm{O}_{2}\right)$ and forced expiratory volume in $1 \mathrm{~s}\left(\mathrm{FEV}_{1}\right)$ at baseline. \% pred: \% predicted.

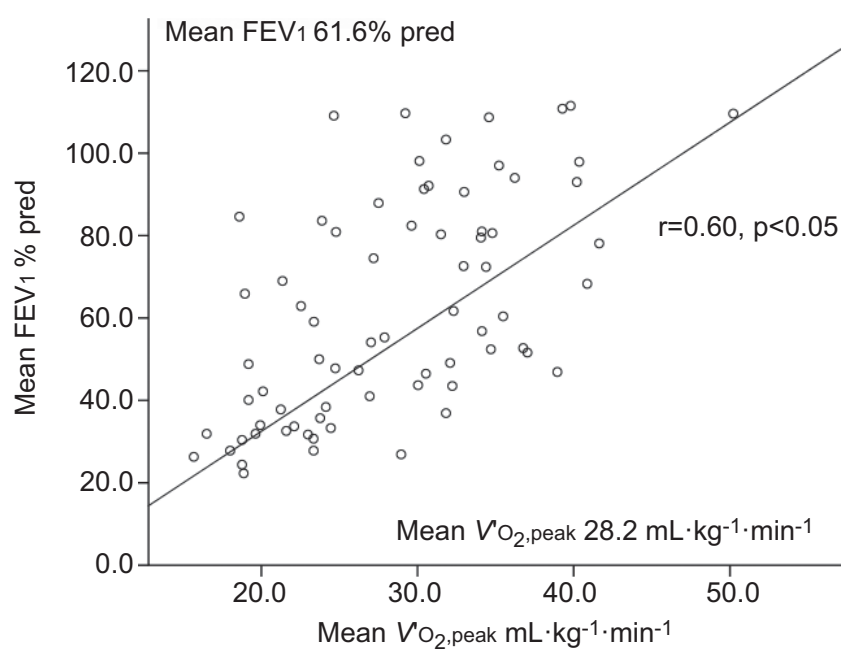

FIGURE 3. Relationship between mean peak oxygen uptake $\left(V^{\prime} \mathrm{O}_{2}\right.$,peak $)$ and mean forced expiratory volume in $1 \mathrm{~s}(\mathrm{FEV} 1)$ at baseline. \% pred: \% predicted.

consistent with the literature on exercise in CF $[1,2,4,9,18]$. Furthermore, our study demonstrated that the initial level of fitness had significant effects on maximal and submaximal fitness parameters. Higher improvements were observed in peak $V^{\prime} \mathrm{O}_{2}$ in the MFL group (+9.6\%) and the LFL group $(14.9 \%)$ compared with the HFL group (+5.1\%) and at VAT by $11.9 \%$ in the LFL group, $9.5 \%$ in the MFL group and $6.1 \%$ in the HFL group.

Our results are in line with previous studies in healthy non-CF people, showing an inverse relationship between the levels of fitness at baseline and the magnitude of improvement in $V^{\prime} \mathrm{O}_{2}$,peak and suggesting a normal training response in CF $[5,13]$. These findings are of particular interest because NIXON et al. [10] and PIANOSI et al. [19] have shown that the likelihood of survival is greater in $\mathrm{CF}$ with a higher level of aerobic fitness. As expected, $V^{\prime} \mathrm{O}_{2}$,peak was found to correlate with FEV1 (fig. 3), but FEV1 had no effect on $\Delta V^{\prime} \mathrm{O}_{2}$. This lack of a relationship of lung function parameters, specifically $\mathrm{FEV} 1$, with changes in $V^{\prime} \mathrm{O}_{2}$, peak was surprising and indicates that the responsiveness to training in $\mathrm{CF}$ is independent of severity of lung disease (figs 1 and 2).

The beneficial effects of the exercise programme may be seen primarily as physiological training effects and can be explained largely by cardiovascular adaptations (improved cardiac output and oxygen extraction to the tissue) $[13,15]$. The increase in $\mathrm{O}_{2}$ pulse, despite unchanged $f c$, suggests an increase in cardiac stroke volume, and therefore true improvement in cardiopulmonary fitness, and not just a better effort on the post-training test [13]. Aerobic training alone has been shown to increase strength in children with CF [20]. Although skeletal muscle strength was not tested in the present study, improvements of peak and submaximal exercise capacity could be associated with a greater strength improvements especially in the LFL group $[18,20]$. Furthermore, better nutritional status may have a positive effect on lung function and exercise capacity [21, 22].

When the $V^{\prime} \mathrm{O}_{2}$,peak of our participants was compared with published normative data of healthy, non-CF populations, a lower $V^{\prime} \mathrm{O}_{2}$,peak was observed in all $\mathrm{CF}$ groups [13]. Some factors can explain these lower values. In our study, cycle 
ergometer testing was used to assess exercise capacity, which may result in a lower $V^{\prime} \mathrm{O}_{2}$, peak value than treadmill testing [13]. Cycle exercise may be unfamiliar to subjects with CF who are unfit and/or have impaired skeletal muscle strength, and this may result in leg fatigue before cardiopulmonary or ventilatory limitation is reached [13].

Healthy individuals use $50-70 \%$ of the ventilatory capacity at peak exercise. The $V^{\prime} \mathrm{E} / \mathrm{MVV}$ at peak exercise in our subjects was higher $(>70 \%)$, which suggests that the ventilatory limit has been reached before the subjects reached their cardiovascular limit $[13,15]$. The fact that MFL and LFL subjects increased their already high $V^{\prime} \mathrm{E} / \mathrm{MVV}$ after training suggests that these lessfit subjects might also have increased their tolerance of dyspnoea [23]. $f C$ values at peak exercise in all groups were low compared with normal values at maximum [13, 15], supporting a physiological limitation due to ventilatory capacity, in addition the aforementioned factors.

The VAT is a useful, reproducible method with which to determine aerobic fitness in healthy adults and children, as well as in $\mathrm{CF}$, and especially for those who cannot perform a maximal incremental cycling test $[24,25]$. In healthy untrained people, the VAT occurs at intensities between $50-60 \%$ of $V^{\prime} \mathrm{O}_{2}$,peak and rarely surpasses $60 \%$ of $V^{\prime} \mathrm{O}_{2}$,peak [26]. However, VAT occurred at a higher percentage of $V^{\prime} \mathrm{O}_{2}$,peak in subjects with chronic disease, reaching up to $75 \% V^{\prime} \mathrm{O}_{2}$,peak, which could be explained by an attenuated rise of $V^{\prime} \mathrm{O}_{2}$ above VAT or an exceptionally low exercise tolerance [13]. The VAT \% in our subjects was between $68 \%$ and $74 \%$ of the $V^{\prime} \mathrm{O}_{2}$,peak. The phenomenon of an attenuated rise of $V^{\prime} \mathrm{O}_{2}$ above $\mathrm{VAT}$ might partly explain the higher percentage of VAT. Other factors, such as altered gas exchange, slowed oxygen uptake kinetics and an early onset of peripheral muscle weakness, might contribute to the higher values [26, 27].

Lung function values increased significantly only in the MFL and LFL groups. Daily chest physiotherapy was part of the intensive care programme. The present study did not include a randomised parallel-group design. Thus, it is difficult and somewhat speculative to discuss whether the exercise programme, the chest physiotherapy or nutritional supplementation has a more pronounced effect on changes in lung function [21, 28].

Some limitations of the study should be taken into account in the discussion of the results. The subjects were recruited and the collection of data was carried out during an in-patient rehabilitation course, which could be seen as a bias of selection. It is possible that more people with CF with advanced lung function and/or low exercise tolerance take part in this additional type of therapy compared with those with a better lung function and/ or only slightly reduced exercise tolerance. This may be one explanation for the low number of participants in the HFL group.

Due to the many facets of the in-patient rehabilitation course (medical treatment, nutritional supplementation, exercise, airway clearance therapy, psychological counselling, and CFspecific education of children, adolescents, adults and their families), it is difficult to assign the greatest effect for the observed changes to any single factor.

We asked the participants about their habitual physical activity at home with a short self-administered questionnaire. However, this questionnaire has not been validated, so we do not know how the subjects' habitual activity levels compare group-to-group.

In conclusion, this study demonstrated that a 6-week exercise training programme increased peak and submaximal exercise capacity in people with $\mathrm{CF}$ with a wide range of lung function and fitness levels. The responses to training showed differences between groups, with the initial fitness level determining those responses. A correlation was found between initial fitness level at peak and effect on $\Delta V^{\prime} \mathrm{O}_{2}$ but not between initial FEV1 and $\Delta V^{\prime} \mathrm{O}_{2}$. The improvements in exercise parameters at VAT were higher in participants with lower pre-training fitness level and lung function. The changes in fitness seen in the present study were similar to the changes observed in healthy persons who undertake exercise training, suggesting that people with $\mathrm{CF}$, regardless of disease severity, respond in a similar way to exercise as do healthy untrained persons.

\section{STATEMENT OF INTEREST}

None declared.

\section{REFERENCES}

1 Bradley J, Moran F. Physical training for cystic fibrosis. Cochrane Database Syst Rev 2008; 1: CD002768.

2 Gruber W, Orenstein DM, Braumann KM, et al. Health-related fitness and trainbility in children with cystic fibrosis. Pediatr Pulmonol 2008; 43: 953-964.

3 Troosters T, Langer D, Vrijsen B, et al. Skeletal muscle weakness, exercise tolerance and physical activity in adults with cystic fibrosis. Eur Respir J 2009; 33: 99-106.

4 Wilkes DL, Schneiderman JE, Nguyen T, et al. Exercise and physical activity in children with cystic fibrosis. Paediatr Respir Rev 2009; 10: 105-109.

5 Skinner JS, Jaskoloski A, Jaskoloska A, et al. Age, sex, race, initial fitness, and response to training: the HERITAGE Family Study. J Appl Physiol 2001; 90: 1770-1776.

6 Boucher GP, Lands LC, Hay JA, et al. Activity levels and the relationship to lung function and nutritional status in children with cystic fibrosis. Am J Phys Med Rehabil 1997; 76: 311-315.

7 Selvadurai HC, Blimkie CJ, Cooper PJ, et al. Gender differences in habitual activity in children with cystic fibrosis. Arch Dis Child 2004; 89: 928-933.

8 Cerny FJ, Cropp GJA, Bye MR. Hospital therapy improves exercise tolerance and lung function in cystic fibrosis. Am J Dis Child 1984; 138: 261-265.

9 Gruber W, Orenstein D, Braumann KM, et al. Effects of an exercise program in children with cystic fibrosis - are there differences between females and males? J Pediatr 2011; 158: 58-63.

10 Nixon $\mathrm{P}$, Orenstein D, Kelsey $\mathrm{S}$, et al. The prognostic value of exercise testing in patients with cystic fibrosis. N Engl J Med 1992; 327: $1785-1788$

11 Orenstein DM. Assessment of exercise pulmonary function. In: Rowland TW, ed. Pediatric Laboratory Exercise Testing. Champaign, Human Kinetics, 1993; pp. 141-163.

12 Miller MR, Hankinson J, Brusasco F, et al. ATS/ERS Task Force: standardization of lung function testing series. Standardization of spirometry. Eur Respir J 2005; 26: 319-338.

13 Cooper CB, Storer TW. Exercise Testing and Interpretation. A Practical Approach. Cambridge, Cambridge University Press, 2001.

14 Godfrey S. Exercise Testing in Children. Applications in Health and Disease. Philadelphia, WB Saunders, 1974. 
15 Orenstein DM, Gruber W. Exercise: testing. In: Hodson M, Geddes D, Bush A, eds. Cystic Fibrosis. 3rd Edn. London, Hodder Arnold, 2007; pp. 353-360.

16 Anderson GS, Rhodes EC. A review of blood lactate and ventilation methods of detecting transition thresholds. Sports Med 1989; 8: 43-55.

17 Beaver W, Wasserman K, Whipp BJ. A new method for detecting the anaerobic threshold. J Appl Physiol 1986; 60: 2020-2027.

18 Selvadurai HC, Blimkie CJ, Meyers N, et al. Randomized controlled study of in-hospital exercise training programs in children with cystic fibrosis. Pediatr Pulmonol 2002; 33: 194-200.

19 Pianosi P, LeBlanc J, Almudevar A. Peak oxygen uptake and mortality in children with cystic fibrosis. Thorax 2005; 60: 50-54.

20 Orenstein DM, Hovell MF, Mulvihill M, et al. Strength vs aerobic training in children with cystic fibrosis. Chest 2004; 126: 1204-1214.

21 Lands LC, Heigenhauser GJF, Jones NL. Analysis of factors limiting maximal exercise performance. Clinical Science 1992; 83: 391-397.

22 Marcotte JE, Grisdale RK, Levison H, et al. Multiple factors limit exercise capacity in cystic fibrosis. Pediatr Pulmonol 1986; 2: 274-281.
23 Gigliotti F, Coli C, Bianchi R, et al. Exercise training improves exertional dyspnea in patients with COPD evidence of the role of mechanical factors. Chest 2003; 123: 1974-1802.

24 Barry SC, Gallagher CG. The repeatability of submaximal endurance exercise testing in cystic fibrosis. Pediatr Pulmonol 2007; 42: 75-81.

25 Nikolaizik WH, Knöpfli B, Leister E, et al. The anaerobic threshold in cystic fibrosis: comparison of v-slope method, lactate turn points, and Conconi test. Pediatr Pulmonol 1998; 25: 147-153.

26 Meyer T, Lucia A, Earnest CP, et al. A conceptual framework for performance diagnosis and training prescription from submaximal gas exchange parameters - theory and application. Int J Sports Med 2005; 26: Suppl. 1, S38-S48.

27 Hebestreit H, Hebestreit A, Trusen A, et al. Oxygen uptake kinetics are slowed in cystic fibrosis. Med Sci Sports Exerc 2005; 37: 10-17.

28 Bradley J, Moran F, Elborn S. Evidence for physical therapies (airway clearance and physical training) in cystic fibrosis: a review of five Cochrane reviews. Respir Med 2006; 100: 191-201. 